Article

\title{
Identification of Potential Nematicidal Compounds against the Pine Wood Nematode, Bursaphelenchus xylophilus through an In Silico Approach
}

\author{
Gnanendra Shanmugam ${ }^{1}$ (D), Sun Keun Lee ${ }^{2}$ and Junhyun Jeon ${ }^{1, *(D)}$ \\ 1 Department of Biotechnology, College of Life and Applied Sciences, Yeungnam University, \\ Gyeongsan 38541, Korea; gnani.science@gmail.com \\ 2 Division of Forest Insect Pests and Diseases, National Institute of Forest Science, Seoul 02455, Korea; \\ lskyou@korea.kr \\ * Correspondence: jjeon@yu.ac.kr; Tel.: +82-2-810-3030 \\ Academic Editor: Paula Gomes
}

Received: 7 June 2018; Accepted: 18 July 2018; Published: 23 July 2018

\begin{abstract}
Bursaphelenchus xylophilus is a destructive phytophagous nematode that mainly infects pine species and causes pine wilt disease (PWD). PWD is one of the most devastating diseases that has damaged the pine forests of eastern Asia and Portugal for the last four decades. B. xylophilus infects healthy pine trees through Monochamus beetles and its subsequent proliferation results in destruction of the infected pine trees. The poor water solubility and high cost of currently used trunk-injected chemicals such as avermectin and abamectin for the prevention of PWD are major concerns. Thus, for the identification of new compounds targeting the different targets, five proteins including cathepsin L-like cystein proteinase, peroxiredoxins, hsp90, venome allergen protein and tubulin that are known to be important for development and pathogenicity of B. xylophilus were selected. The compounds were virtually screened against five proposed targets through molecular docking into hypothetical binding sites located in a homology-built protein model. Of the fifteen nematicides screened, amocarzine, mebendazole and flubendazole were judged to bind best. For these best docked compounds, structural and electronic properties were calculated through density functional theory studies. The results emphasize that these compounds could be potential lead compounds that can be further developed into nematicidal chemical against B. xylophilus. However, further studies are required to ascertain the nematicidal activity of these compounds against phytophagous nematode.
\end{abstract}

Keywords: Bursaphelenchus xylophilus; pine wood nematode; nematicidal compounds; amocarzine; flubendazole; molecular docking; density functional theory

\section{Introduction}

The pine wood nematode Bursaphelenchus xylophilus is a migratory endoparasitic nematode causing pine wilt disease (PWD). This pine wood nematode (PWN) has caused severe damage to the forest ecosystems of Far East Asian countries [1] and North America [2]. Since its first report in Japan in 1905 [3], PWN has become an economically important pest throughout the East Asian countries [4]. Spread of this notorious invasive species to Portugal and Spain in Europe has posed the serious threat to the pine forests across the globe [5]. This phytoparasitic nematode can be transmitted from dead tree to healthy trees through pine sawyer beetle vectors (Monochamus spp.) [6]. Unlike other species in the Bursaphelenchus genus, B. xylophilus, which possess both phytophagus and mycophagus feeding strategies, are unique [7]. The nematode feeds on the parenchyma cells by migrating through resin canals and causes wilting of pine trees. Once the pine trees are dead, the nematode starts feeding on the fungi (Botrytis cinerea) that colonize the dead trees [8]. 
In general, the fumigation of affected trees with metam-sodium, control of Japanese sawyer beetle vectors (the only vector of PWN) with aerial application of insecticides (fenitrothion and thiacloprid) and the trunk injections of nematicides such as avermectin, abamectin, morantel tartarate and levamisole hydrochloride are currently practiced as control measures $[9,10]$. However, the poor solubility and higher cost are the greater concerns in the usages of trunk injections to control the PWN. Likewise in Trichostrongylus colubriformis and Ostertagia circumcincta resistance to ivermectin [11], in near future the concern about B. xylophilus developing resistance to avermectin, abamectin, morantel tartarate and levamisole hydrochloride due to their continuous usage may occur. However, PWN has not yet been reported to show resistance, there are several other pest insects that have developed resistance to emamectin benzoate, one of nematicidal compounds the most widely used as a trunk injection agent in China [12-15]. Thus the identification of novel targets, compounds that act as antinematodal agents and elucidating their mechanism of action might serve the purpose.

The availability of the completely sequenced genome of $B$. xylophilus has opened up the possibility of investigating the most prominent proteins that play a crucial role in the survival and parasitism of the nematode as novel drug targets [16,17]. Hence in this study, cathepsin L-like cysteine proteinase that is involved in post embryonic development [18], 2-cysteine peroxiredoxins that regulates reproduction and pathogenecity [19], heat shock protein 90 (HSP90) that helps adaptation to different climatic conditions [20], venom allergen proteins (VAP) that manifests the invasion of parasitic genes [21] and tubulin that regulates the microtubule, mitosis and motility [22,23] of B. xylophilus are considered as drug targets. In general, the anti-nematode drugs are classified into two main types based on their target sites, such as drugs targeting membrane ion channels and other class of drugs that acts on biochemical targets. Thus, in this present study, the compounds belonging to the benzimidazole, imidazothiazole and tetrahydropyrimidines compound classes that act on biochemical targets are selected for virtual screening. The virtual screening was carried out to reveal the better binding affinities against these targets as potential alternatives of PWN control agents. In addition, structural and electronic properties of best compounds were calculated through density functional theory (DFT) studies to explore the sites of chemical reactivity that are vital for the compounds for the possible interactions with receptors. The results emphasize that a nematicidal compound that binds to more than one drug target can be used to more effectively control PWD, instead of using the chemical agent that bind to single specific drug target.

\section{Results and Discussion}

In last few decades, virtual screening strategies such as molecular docking have made a significant impact on the discovery of promising new drug leads [24]. Many research groups have put forth the usage of these molecular docking methods to screen potential novel compounds against various diseases [25]. By employing similar approaches, eight phenylpropanoids were reported as inhibitors against a migratory endoparasitic nematode, Radopholus similis, which causes necrosis of plant tissues and massive destruction in host plants [26]. In the present study, we have explored the binding efficiencies of compounds with nematicidal activity through docking studies against five potential targets from B. xylophilus (Table 1). All the compounds included in the study exhibited docking interactions with all five protein targets. However, amocarzine, flubendazole and mebendazole are considered to be the best in terms of their binding energies against all the five target proteins, when compared to the inactive antihelmenthic compound, chloramphenicol (see below).

Table 1. The selected potential drug targets from B. xylophilus and its functions.

\begin{tabular}{ccc}
\hline S1. No. & Target & Function \\
\hline 1. & Cathepsin L-like cystein proteinase (BxCLCP) (UniProt ID: Q6LDJ1) & Post embryonic development \\
2. & 2-cysteine peroxiredoxin (BxPRX) (UniProt ID: B0LFQ7) & Reproduction and pathogenecity \\
3. & Heat Shock Protein 90 (BxHSP90) (UniProt ID: A4UU63) & Adapts to different climatic conditions \\
4. & Venom allergen Protein-3 (BxVAP-3) (UniProt ID: E0WW94) & Invasion parasitic genes \\
5. & $\beta$-Tubulin (BxTUB) (UniProt ID: D1MX18) & Microtubule, mitosis, motility \\
\hline
\end{tabular}




\subsection{Target-Template Alignment for Homology Modeling}

The BLASTP [27] analysis of target sequence such as cathepsin L-like cysteine proteinase (BxCLCP), 2-cysteine peroxiredoxins (BxPRX), heat shock protein 90 (BxHSP90), venom allergen protein-3 (BxVAP-3) and tubulin protein (BxTUB) sequence against protein databank (PDB) [28] identified 1CS8, 1QMV, 5FWP, 4NUI and 5IJ0 X-ray crystal structures as homologous proteins respectively. These $X$-ray crystal structures shared sequence identity of $56.88 \%, 74.61 \%, 74.86 \%, 40.94 \%$ and $86.38 \%$ with the five target proteins, which significantly implies that they were functionally related. Hence these proteins were considered as templates for homology modelling. Further, these templates were analyzed for its resolution, sequence similarity and secondary structure similarity covering the maximum range of target sequence. Few studies have demonstrated that sequence identity higher than $25 \%$ between two proteins are similar in 3D structures $[29,30]$. Hence, the 3D structures of respective templates were considered to be suitable for homology modeling.

\subsection{Homology Modeling}

The template-target sequence alignment files were used to generate the 3D models of BxCLCP, BxPRX, BxHSP90, BxVAP-3 and BxTUB by using the template structure co-ordinates in homology modeling tool, Modeler9v9 [31].

The Discrete Optimized Protein Energy (DOPE) score of the models revealed the structural compatibility [32]. These modelled structures of BxCLCP, BxTUB, BxVAP-3 and BxHSP90 (Supplementary Figures S1-S4) and BxPRX (Figure 1a) were considered for further analysis, as they exhibited the lowest DOPE assessment score and minimized energy.

\subsection{Model Validation}

The qualities of the modelled structures was assessed through online quality evaluation tools such as PROCHECK, ERRAT and Verify 3D, which are provided through Structural Analysis and Verification Server (SAVES) [33] of UCLA-DOE Lab. The phi and psi angles that explore the stereo-chemical parameters of the energy-minimized models were determined by using PROCHECK [34]; the 1D-3D structure compatibility of the best models by Verify 3D [35] and the regions of the modelled structure that can be rejected at the $95 \%$ and $99 \%$ confidence intervals were predicted through ERRAT programs [36]. The Ramachandran plot (RC plot) of all the generated models reveals that the built models are best as they exhibited more number of residues in the most favorable regions (Supplementary Table S1), while low number of residues are observed in disallowed region of RC plot (Figure 1b). Also, the ERRAT plot (Figure 1c) and Verify 3D measuring quality factor values supported that the built models are relevant, reliable and of good quality (Supplementary Table S1). 


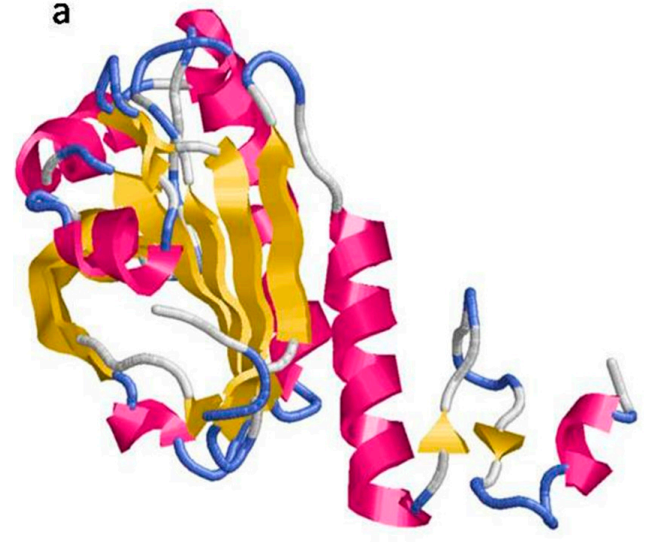

b

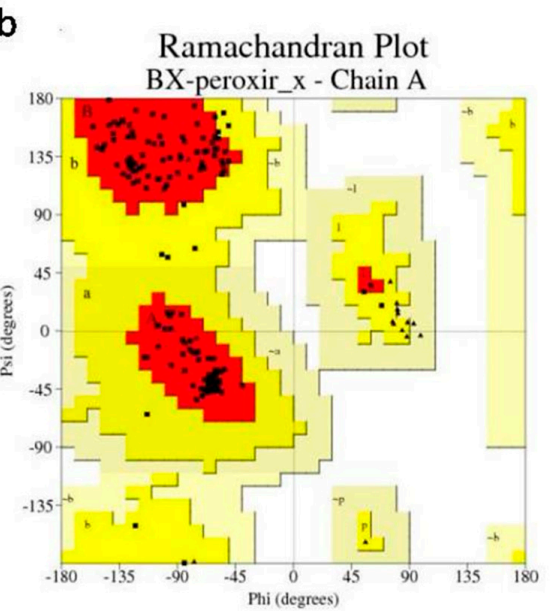

C

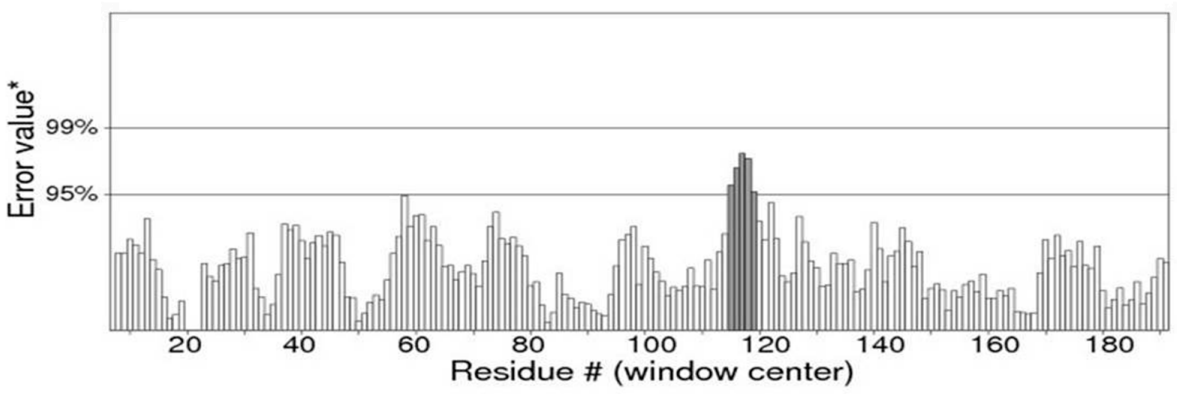

Figure 1. Theoretical model of 2-cysteine peroxiredoxin structure and model validation through SAVES server. (a) The 3D structure of built protein in cartoon representation and structure colors: Helices (magenta), Sheets (yellow) and turns/loops (blue); (b) Model validation by Ramachandran plot; (c) The ERRAT Plot shows that the generated model has high resolution since only a small stretch of 5 amino acids in the modelled structure needs to be rejected at a confidence level greater that $95 \%$.

\subsection{Structure-Based Virtual Screening}

The modelled proteins were submitted to the CASTp server [37] to predict binding sites. From the predicted binding sites, the sites with larger volumes were used for further docking interaction with the anti-nematode compounds. Further, these binding pockets were assessed for docking with active (mebendazole) and in-active antihelmenthic compound (chloramphenicol). The pocket with higher binding affinity for active compound, mebendazole from each target was selected for further docking studies with 15 nematicidal compounds. Eventually, antihelmenthic compound with predicted molecular properties confined to the drug-like properties (based on Lipinski's rule of five) and biological activity prediction (antihelmentics) at PASS (Predicted Activity Spectrum of Small Molecules) server [38] resulted in 15 compounds. These 15 FDA approved antihelmenthic compound were selected for further docking studies, as they can be easily used for drug repurposing and reformulation. The evaluation of drug-likeness of compounds is an essential part of drug discovery especially at the initial stages [39]. By considering the physicochemical properties of a compound using in silico approaches, its molecular impact in terms of in-vivo biological activity can be determined. The biological activity predicted at PASS server reveals the activities of compounds as active and inactive in its respective lab experiments. The biological activity spectrum at PASS server (Pa-Pi values) varies from 0.000 to 1.000 . In PASS prediction, if the biological activity value of a compound is $\mathrm{Pa}>0.5$, then that compound is expected to reveal the activity in in-vivo and in-vitro experiments. If $\mathrm{Pa}>0.7$, then the compound is very likely to exhibit good activity in the experiments. The biological activity at PASS server is predicted for antihelminthic properties of all the 15 compounds (Supplementary 
Table S2). Further, the drug-like properties that satisfy the Lipinski's rule of five, which is also considered to be essential for rational drug design, were also determined. It is observed that all the selected 15 compounds showed no violation of Lipinski's rule of five [40] (Supplementary Table S3), i.e., $\leq 5$ hydrogen bond donors, $\leq 10$ hydrogen bond acceptors, $<500$ dal of molecular weight, $<5$ partition coefficient $(\log \mathrm{P}),<10$ rotatable bonds, topological polar surface area (TPSA) $<140$.

To explore the binding efficacy and the molecular basis of interactions, the nematicidal compounds were docked within the predicted binding sites of all five modelled protein targets from B. xylophilus. All 15 nematicidal compounds exhibited docking poses with better binding affinities (in terms of docking score) against all five target proteins from B. xylophilus (Supplementary Table S3), when compared to inactive compound, chloramphenicol (BxCLCP: $-1.0258 \mathrm{~kJ} / \mathrm{mol}$; BxPRX: $-1.1087 \mathrm{~kJ} / \mathrm{mol}$; BxHSP90: $-1.0122 \mathrm{~kJ} / \mathrm{mol}$; BxVAP-3: $-1.1453 \mathrm{~kJ} / \mathrm{mol}$; BxTUB: $-2.4862 \mathrm{~kJ} / \mathrm{mol}$ ). The binding energies and amino acids interactions of each compound against each target were given in Supplementary Tables S4-S8. From the docking results, it is evident that all the compounds exhibited binding energy against each targets.

The binding energies of all 15 compounds with five targets were given in Table 2. Although, all the compounds exhibited binding conformations in the active site pocket with both H-bond and non-bonded interaction, amocarzine, flubendazole and mebendazole exhibited better interaction (based on binding energies) with all five targets (Table 3).

Table 2. The binding energies $(\mathrm{kJ} / \mathrm{mol})$ of all compounds with all five target proteins from B. xylophilus.

\begin{tabular}{|c|c|c|c|c|c|}
\hline $\begin{array}{l}\text { Compound } \\
\text { Name } \\
\text { (Pubchem Id) }\end{array}$ & $\begin{array}{l}\text { Cathepsin L-Like } \\
\text { Cystein Proteinase } \\
\text { (BxCLCP) }\end{array}$ & $\begin{array}{l}\text { 2-Cysteine } \\
\text { Peroxiredoxin } \\
\text { (BxPRX) }\end{array}$ & $\begin{array}{l}\text { Heat Shock } \\
\text { Protein } 90 \\
\text { (BxHSP90) }\end{array}$ & $\begin{array}{c}\text { Venom Allergen } \\
\text { Protein-3 (BxVAP-3) }\end{array}$ & $\begin{array}{c}\beta \text {-Tubulin } \\
\text { (BxTUB) }\end{array}$ \\
\hline $\begin{array}{l}\text { Kainic acid } \\
\text { (CID 10255) }\end{array}$ & -17.653 & -18.586 & -11.942 & -12.681 & -24.909 \\
\hline $\begin{array}{l}\text { Carbendazim } \\
\text { (CID 25429) }\end{array}$ & -14.879 & -16.525 & -12.365 & -15.173 & -21.44 \\
\hline $\begin{array}{l}\text { Naphthalen-2-ol } \\
\text { (CID 8663) }\end{array}$ & -9.5734 & -11.793 & -9.6124 & -11.458 & -12.053 \\
\hline $\begin{array}{c}\text { Pyrantel } \\
\text { (CID 708857) }\end{array}$ & -8.0396 & -12.548 & -8.519 & -9.0794 & -12.559 \\
\hline $\begin{array}{c}\text { Closantel } \\
\text { (CID 42574) }\end{array}$ & -15.618 & -6.0856 & -8.3846 & -15.835 & -14.155 \\
\hline $\begin{array}{l}\text { Thiabendazole } \\
\text { (CID 5430) }\end{array}$ & -12.071 & -15.395 & -12.1 & -13.143 & -16.532 \\
\hline $\begin{array}{l}\text { Schaftoside } \\
\text { (CID 442658) }\end{array}$ & -10.435 & -9.6139 & -4.0356 & -5.3029 & -22.876 \\
\hline $\begin{array}{l}\text { Mebendazole } \\
\text { (CID 4030) }\end{array}$ & -18.322 & -20.111 & -18.993 & -18.699 & -25.531 \\
\hline $\begin{array}{l}\text { Oxfendazole } \\
\text { (CID 40854) }\end{array}$ & -15.653 & -19.8592 & -13.344 & -17.071 & -21.242 \\
\hline $\begin{array}{l}\text { Levamisole } \\
\text { (CID 26879) }\end{array}$ & -8.1927 & -12.361 & -6.1674 & -12.326 & -13.724 \\
\hline $\begin{array}{l}\text { Tetramizole } \\
\text { (CID 3913) }\end{array}$ & -6.7261 & -10.75 & -5.2535 & -12.811 & -17.188 \\
\hline $\begin{array}{l}\text { Coumafos } \\
(\text { CID 2871) }\end{array}$ & -6.7703 & -18.175 & -1.7963 & -5.8927 & -15.065 \\
\hline $\begin{array}{l}\text { Amocarzine } \\
\text { (CID 5464102) }\end{array}$ & -18.752 & -30.163 & -22.895 & -19.279 & -27.122 \\
\hline $\begin{array}{l}\text { Fenbendazole } \\
\text { (CID 3334) }\end{array}$ & -14.391 & -18.826 & -14.743 & -14.202 & -24.141 \\
\hline $\begin{array}{c}\text { Flubendazole } \\
\text { (CID 35802) }\end{array}$ & -19.364 & -23.2623 & -15.053 & -17.962 & -28.058 \\
\hline
\end{tabular}


Table 3. Amino acids in the binding pockets of the targets proteins favoring H-bond and non-bonded interactions with best docked compounds: Amocarzine, flubendazole and Mebendazole.

\begin{tabular}{|c|c|c|c|}
\hline \multirow{2}{*}{$\begin{array}{c}\text { Potential Targets from } \\
\text { B. xylophilus }\end{array}$} & \multicolumn{3}{|c|}{ Best Docked Compounds } \\
\hline & $\begin{array}{l}\text { Amocarzine } \\
\text { (CID 5464102) }\end{array}$ & $\begin{array}{l}\text { Flubendazole } \\
\text { (CID 35802) }\end{array}$ & $\begin{array}{l}\text { Mebendazole } \\
\text { (CID 4030) }\end{array}$ \\
\hline \multirow[t]{2}{*}{$\begin{array}{l}\text { Cathepsin L-like cystein } \\
\text { proteinase (BxCLCP) } \\
\text { (UniProt ID: Q6LDJ1) }\end{array}$} & $\begin{array}{c}\text { \#Gln26*, His27 } \\
\text { \#Glu28*, Lys113 } \\
\text { Thr206* }\end{array}$ & $\begin{array}{l}\text { Ile25*, \#Gln62* } \\
\text { \#Cys65*, Gly66 } \\
\text { Cys68, Thr206* } \\
\text { His207, Trp230 }\end{array}$ & $\begin{array}{c}\text { \#Gln62 * \#Cys65 * } \\
\text { Gly66, \#Trp230 * }\end{array}$ \\
\hline & -18.752 & -19.364 & -18.322 \\
\hline \multirow{2}{*}{$\begin{array}{c}\text { 2-cysteine peroxiredoxin } \\
\text { (BxPRX) } \\
\text { (UniProt ID: B0LFQ7) }\end{array}$} & $\begin{array}{c}\text { Ile6, Arg137* } \\
\text { Gln138, Ile139* } \\
\text { Leu156, Glu152 * } \\
\text { Phe160 }\end{array}$ & $\begin{array}{c}\text { Ile6, Arg137* } \\
\text { \#Gln138*,\#Ile139*, } \\
\text { Phe160 }\end{array}$ & $\begin{array}{c}\text { Ile6, Arg137* } \\
\text { Gln138, \#Ile139* } \\
\text { Phe160 }\end{array}$ \\
\hline & -30.163 & -23.2623 & -20.111 \\
\hline \multirow[t]{2}{*}{$\begin{array}{l}\text { Heat Shock Protein } 90 \\
\text { (BxHSP90) } \\
\text { (UniProt ID: A4UU63) }\end{array}$} & $\begin{array}{c}\text { \#Lys332 *, Ala333 } \\
\text { Gln334, \#Arg337* } \\
\text { Asp338, Ser339 } \\
\text { Met342 }\end{array}$ & $\begin{array}{c}\text { \#Met331*, Lys332 } \\
\text { \#Gln334* Ala335, } \\
\text { \#Arg337* }\end{array}$ & $\begin{array}{l}\text { Met331 *, Lys332 } \\
\text { Ala333, Gln334* } \\
\text { Ala335, \#Arg337 * }\end{array}$ \\
\hline & -22.895 & -15.053 & -18.993 \\
\hline \multirow{2}{*}{$\begin{array}{c}\text { Venom allergen Protein-3 } \\
\text { (BxVAP-3) } \\
\text { (UniProt ID: E0WW94) }\end{array}$} & $\begin{array}{l}\text { \#Trp95 * \#Pro96 * } \\
\text { His97, \#Asn160 * }\end{array}$ & $\begin{array}{c}\text { Ala93, Gln94 } \\
\text { \#Trp95* , \#Asn160 *, } \\
\text { Trp161 }\end{array}$ & $\begin{array}{c}\text { Ala93, Gln94 } \\
\text { \#Trp95*, \#Asn160 * } \\
\text { Trp161 }\end{array}$ \\
\hline & -19.279 & -17.962 & -18.699 \\
\hline \multirow{6}{*}{$\begin{array}{c}\beta \text {-Tubulin } \\
\text { (BxTUB) } \\
\text { (UniProt ID: D1MX18) }\end{array}$} & Gln11, Gly98* & $\mathrm{G} \ln 11 *$, Cys12 & Gln11, \#Cys12 * \\
\hline & \#Asn99*, Ser138 & \#Asn99 *, Gly141 & Ser138, Gly141 \\
\hline & Gly141, Thr143* & Gly142*, Thr143* & Val169, Ser172* \\
\hline & Ser176, \#Asp177 * & Asp177, Thr178 & \#Asp177*, Asn204* \\
\hline & Glu181, Asn204 & Asn204, Tyr222 & Tyr222 \\
\hline & -27.122 & -28.058 & -25.531 \\
\hline
\end{tabular}

* Residues involved in H-bond interactions; \#* Residues involved in H-bond and non-bonded interactions. The other residues are involved in non-bonded interactions. Binding energies $(\mathrm{kJ} / \mathrm{mol})$ are provided respectively.

The clear understanding of binding modes of these three compounds, amocarzine, flubendazole and mebendazole within the binding site of modelled structures can aid in the design of better nematicidal inhibitors against B. xylophilus. Thus, the docking interactions of amocarzine, flubendazole and mebendazole against all five proteins were analyzed in detail. The binding interactions of these compounds with all targets are stabilized with hydrogen bond and non-bond interactions (Supplementary Figures S5-S8). Generally, the non-bonded interaction is involved to make the protein-ligand complex more stable and establishes non-bonded force (vander waal's) to make the ligands achieving its stable conformation for better activity [41].

In a similar study, Babu et al. [26] virtually screened the phenylpropanoids phytochemicals from Piper nigrum L. (black pepper) against various targets including $\beta-1,4$, endoglucanase, cathepsin B-like cysteine proteinase and glutathione S-transferase from Radopholus similis and also reported the mortality rate through in-vitro assay. Sharma et al. [41] performed the docking interactions of nematicidal compounds with $\beta$-tubulin protein from Brugia malayi and reported albendazol sulfone as best nematicidal (anti-filarial) drug. Taylor et al. [22] has reported the common chokepoint reactions and enzymes in nematodes and prioritized the drug targets and suggested perhexiline as a nematicidal compounds and its binding efficacy against carnitine palmitoyltransferase 2 from Caenorhabditis elegans. In another study, Khanna and Ranganathan [17], reported benzimdazole and piperazine compounds as active compounds targeting acetylcholine and tubulin $\beta-1$ chain receptor from nematodes through in silico approach. They reported that piperazine-like substructures with nitrogen atom in the piperazine ring might be frequently involved in binding to the receptor.

In BxCLCP and BxTUB, flubendazole exhibited better binding energy $(-19.3639 \mathrm{~kJ} / \mathrm{mol}$ and $-28.058 \mathrm{~kJ} / \mathrm{mol})$ followed by amocarzine $(-18.7524 \mathrm{~kJ} / \mathrm{mol}$ and $-27.1220 \mathrm{~kJ} / \mathrm{mol})$ and mebendazole $(-18.3215 \mathrm{~kJ} / \mathrm{mol}$ and $-25.531 \mathrm{~kJ} / \mathrm{mol})$. The binding interactions of flubendazole in BxCLCP are supported by H-bond formations with Ile25, Gln62, Cys65 and Thr206. The hydrophobic (non-bonded) interactions are supported by Gln62, Cys65, Gly66, Cys68, His207 and Trp230. The flubendazole 
interaction with BxTUB is supported by Gln11, Asn99, Gly142 and Thr143, while the non-bonded interactions are supported by Cys12, Asn99, Gly141, Asp177, Thr178, Asn204 and Tyr222.

In BxPRX, amocarzine showed better activity with binding energy of $-30.1634 \mathrm{~kJ} / \mathrm{mol}$, followed by flubendazole $(-23.2623 \mathrm{~kJ} / \mathrm{mol})$ and mebendazole $(-20.1114 \mathrm{~kJ} / \mathrm{mol})$ (Figure 2$)$. The interactions of amocarzine are supported by H-bond formation with Arg137, Ile139 and Glu152. The non-bonded interactions are favoured by Ile6, Gln138, Leu156 and Phe160. Also, in BxHSP90 and BxVAP-3, amocarzine exhibited better binding energy $(-22.8945 \mathrm{~kJ} / \mathrm{mol}$ and $-19.2792 \mathrm{~kJ} / \mathrm{mol})$ followed by mebendazole $(-18.9934 \mathrm{~kJ} / \mathrm{mol}$ and $-18.6991 \mathrm{~kJ} / \mathrm{mol})$ and flubendazole $(-15.0529 \mathrm{~kJ} / \mathrm{mol}$ and $-17.9623 \mathrm{~kJ} / \mathrm{mol})$. The binding interaction of amocarzine in BxHSP90 is favoured by H-bonds by Lys332 and Arg337. The hydrophobic interactions are supported by Lys332, Ala333, Gln334, Arg337, Asp338, Ser339 and Met342. The amocarzine interaction with BxVAP-3 is favoured by H-bond formation with Trp95, Pro96 and Asn160 and non-bonded interactions with Trp95, Pro96, His97 and Asn160.
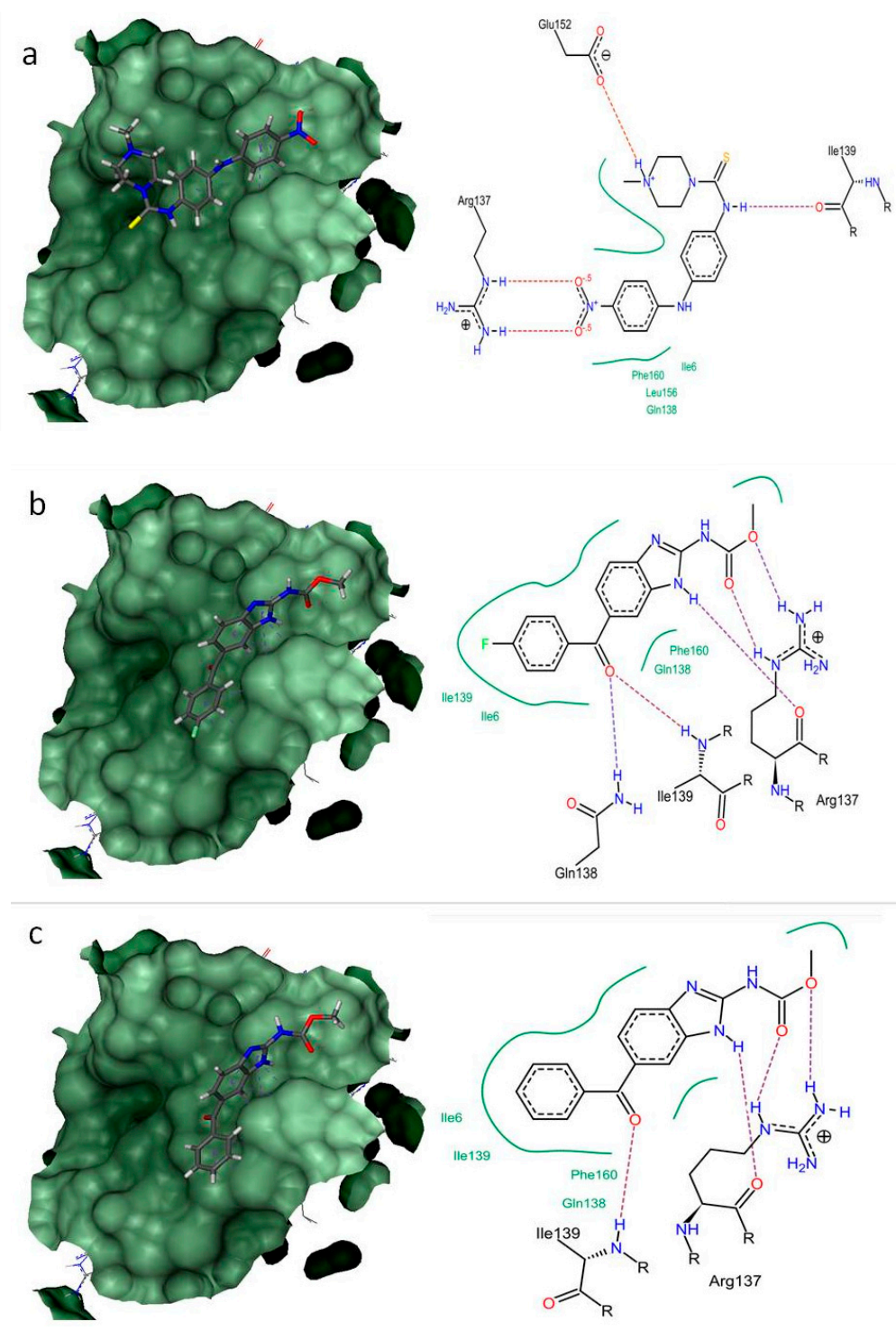

Figure 2. The docking complex and interactions of best docked compounds with 2-cysteine peroxiredoxin from B. xylophilus. (a) Amocarzine (binding energy: $-30.1634 \mathrm{~kJ} / \mathrm{mol}$ ) (b) Flubendazole (binding energy: $-23.2623 \mathrm{~kJ} / \mathrm{mol}$ ) (c) Mebendazole (binding energy: $-20.1114 \mathrm{~kJ} / \mathrm{mol}$ ). 
Thus the present docking studies of amocarzine, flubendazole and mebendazole with chosen protein targets from B. xylophilus implies that the presence of keto groups $(\mathrm{C}=\mathrm{O})$ and amide groups $(-\mathrm{CO}-\mathrm{NH})$ as electronegative elements in the compound were crucial for interactions with binding site residues and for its nematicidal activity. Therefore, these prioritized drug targets and drug compounds may play a pivotal role in the development of new and urgently-needed nematicidal drugs against B. xylophilus.

\subsection{Density Functional Theory Analysis}

Density functional theory (DFT), a quantum mechanical approach is used to describe the accurate structural and electronic properties of compounds. In this study, the electronic distribution information of amocarzine, flubendazole and mebendazole were theoretically determined through orbital energy calculations. The idea on electronic distribution of these compounds could provide the clear picture of protein-ligand interactions and be useful to explore the binding modes of the compounds. The overall high and low electron density regions are better characterized by the electrostatic potentials (Figure 3). The Red and green colour distributions represent positive and negative phase in molecular orbital wave function, respectively. The localizations of the HOMO and LUMO of a ligand are very important because they influence the nature of the interaction with a proposed receptor. The HOMO of the ligand interacts with the LUMO of the receptor and vice versa. Hence, increasing the HOMO energy of the ligand closes the energy gap with the LUMO of the receptor and is expected to enhance binding. Similarly, lowering the LUMO energy of the ligand is expected to enhance binding. An electrostatic potential (ESP) map provides a picture of the overall polarity of a ligand [42].
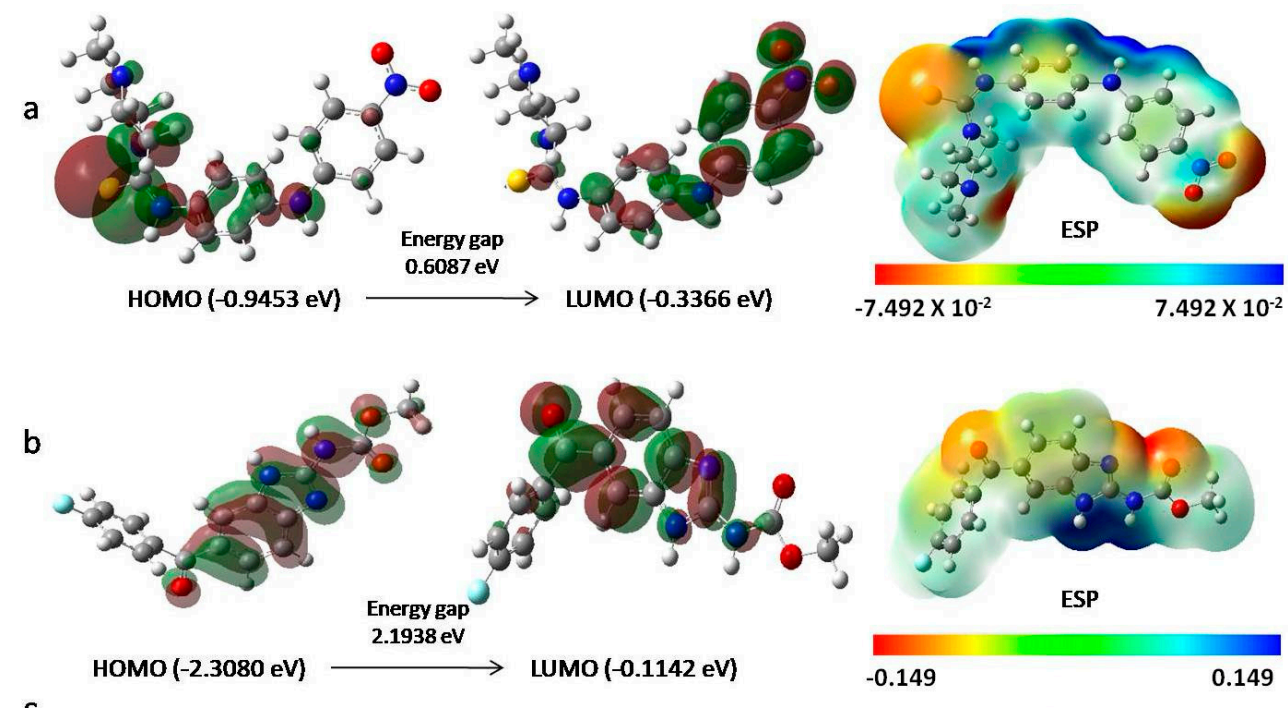

C

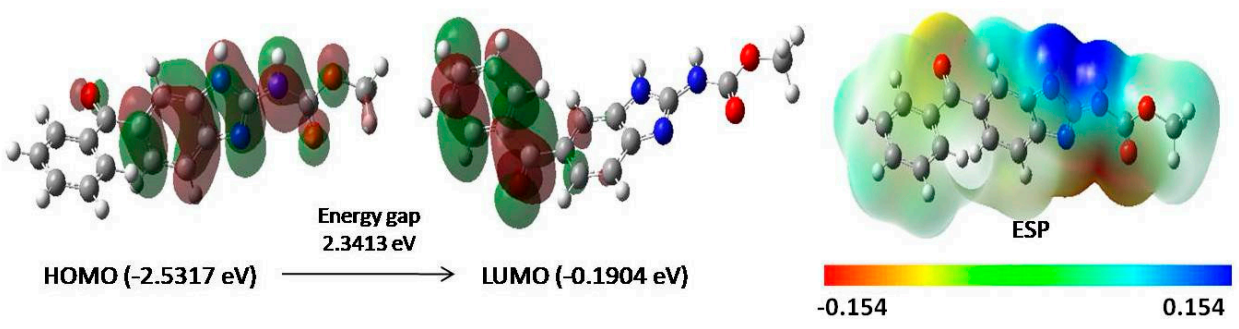

Figure 3. The HOMO-LUMO diagram and ESP maps of best docked compounds. (a) Amocarzine (b) Flubendazole (c) Mebendazole. The positive (red) and negative (green) phase distributions in molecular orbital wave function. HOMO (electron donor regions) determines the ionization potentials. LUMO (electron acceptor regions) determines the electron affinity. The ESP represents electron-rich (red) and electron-poor (blues) regions. The order of electron rich and poor regions are represented in rainbow colors as RED < ORANGE < YELLOW < GREEN < BLUE. 
The HOMO-LUMO diagram and ESP maps shows that the sulphur atom and nitrogen atoms in amocarzine contribute in HOMO and two nitro group oxygen atoms in LUMO (Figure 3a). In mebendazole, the HOMO is contributed by nitrogen and oxygen atoms, while LUMO is contributed by ring carbon atoms (Figure $3 b$ ). The nitrogen and oxygen atom along with ring carbon atoms in flubendazole contributes to HOMO and LUMO (Figure 3c). The HOMO orbital atoms are high electron density region that corresponds to functional groups interactions with the binding site residues within the target proteins as discussed above in structure-based virtual screening.

Among the screened compounds, the compounds that showed less HOMO-LUMO energy gap, low hardness and more softness are amocarzine $(0.6087 \mathrm{eV}, 0.3043 \mathrm{eV}$ and $3.2862 \mathrm{eV})$, flubendazole (2.1938 eV, $1.0969 \mathrm{eV}$ and $0.9116 \mathrm{eV}$ ) and mebendazole (2.3413 eV, $1.1706 \mathrm{eV}$ and $0.8542 \mathrm{eV})$ (Supplementary Table S9). Thus the DFT calculations performed here further substantiate our molecular docking findings.

Eventually, to overcome the resistance development against the continuous usage of pesticides, the choice of novel compounds must have novel targets and different mode of actions. The target of currently used abamectin/avermectin is GABA-gated chloride channel [12]. Thus, the compounds targeting the different targets (biochemical targets) as reported in this study might be an alternative choice for the design of novel nematicidal compounds against B. xylophilus.

In conclusion, this study emphasize that amocarzine, mebendazole and flubendazole compounds can be used as potential lead compounds for the development of an effective nematicidal chemical against B. xylophilus. However their poor water-solubility can be overcome with cyclodextrins (hydroxypropyl- $\beta$-cyclodextrin) that are often used in the formulation of poor hydrosoluble compounds and in-vitro screening could result in a development of commercial trunk injection agent for PWD.

\section{Materials and Methods}

\subsection{Sequence Analysis for Potential Templates}

The five proteins targets, cathepsin L-like cystein proteinase (UniProt ID: Q6LDJ1), 2-cysteine peroxiredoxins (UniProt ID: B0LFQ7), HSP90 (UniProt ID: A4UU63), venom allergen proteins (UniProt ID: E0WW94) and tubulin (UniProt ID: D1MX18) protein sequence of Bursaphelenchus xylophilus was retrieved from UniProtKB database [43]. The most homologous sequence as potential template for homology modeling are obtained by using BLASTP (basic local alignment search tool) [27] similarity search tool against PDB database [28]. The sequence alignment and alignment errors were refined by using ClustalW [44] for homology modeling.

\subsection{Homology Modeling}

Using the homology modeling tool, Modeler9v9 [31], the homology models of five proteins (cathepsin L-like cysteine proteinase, 2-cysteine peroxiredoxins, HSP90, venom allergen proteins and tubulin) from $B$. xylophilus were built by employing the target-template sequence alignment files. A total of five 3D models for each of the target sequences were built from the starting structure of the templates by satisfying the spatial restraints through random generation [32]. Among the generated models, the least root mean square deviation (RMSD) value in comparison with template structure was considered for selecting the best model and its energy was minimized through 20 steps of steepest descent and conjugate gradient by using GROMOS [45] of Swiss-PDB viewer [46], and final energy-minimized model was used for further analysis.

\subsection{Model Validation}

The stereo-chemical parameters of the energy-minimized models were considered to evaluate the quality of the generated models. The phi and psi angles representing the stereo-chemical parameters of the model through PROCHECK [34], the compatibility of a generated 3D structure with its own amino 
acid sequence through Verify3D [35], and the regions of the modelled structure that can be rejected at the $95 \%$ and $99 \%$ confidence intervals through ERRAT [36] were determined at the SAVES server [33].

\subsection{Structure-Based Virtual Screening}

The binding pockets in the modelled structures were predicted by submitting to CASTp (Computed Atlas of Surface Topology of proteins) Server [37]. The binding sites with larger volumes and greater affinity towards active (mebendazole) antihelmenthic compound was selected for further docking studies. For virtual screening, the 15 antihelmenthic compound with predicted drug-like properties and biological activity (antihelmentics) from the ZINC database [47] were used. Docking was performed with 5 proteins of B. xylophilus by using FlexX [48]. The docking parameters were triangle matching base placements, full score (threshold 30) and No score contributions (threshold 70), $2.9 \AA$ clash handling, 0.6 of protein ligand clashes and intra-ligand clash factors and 200 as maximum number of solutions per iteration.

\subsection{Docking Interactions}

The docking interactions of 15 compounds with the binding pocket amino acids of the each target protein was assessed by using pose-view [49], which clearly reveals the H-bond and non-bond interactions. The compounds with the better dock score and interaction were considered for further electronic structure studies.

\subsection{Electronic Structure Study of Selected Screening Compounds}

The molecular electrostatic potential (MEP), which determines polar interactions with the proposed binding sites, and the nature of the highest occupied and lowest unoccupied molecular orbital (HOMO and LUMOs), which determine nucleophilic and electrophilic activity, were calculated by using density functional theory (DFT). The DFT calculations were performed for amocarzine, flubendazole and mebendazole compounds by using functional B3LYP with 6-31G** basic set in Gaussian 09 [50]. The important parameter, HOMO-LUMO orbital energies that are used to assess the ionization energy, electron affinity [51], electro negativity, electronic chemical potential [52], molecular hardness, softness [53] and Electrophilicity index [54] are calculated to reveal the compounds stability and chemical reactivity.

Supplementary Materials: The following are available online, Figure S1: Theoretical model of Cathepsin L-Like cysteine proteinase (BxCLCP) structure and model validation through SAVES server; Figure S2: Theoretical model of Heat Shock Protein 90 (BxHSP90) structure and model validation through SAVES server; Figure S3: Theoretical model of Venom allergen Protein-3 (BxVAP-3) structure and model validation through SAVES server; Figure S4: Theoretical model of $\beta$-Tubulin (BxTUB) structure and model validation through SAVES server; Figure S5: The docking complex and interactions of best docked compounds with Cathepsin L-Like cysteine proteinase (BxCLCP) from B. xylophilus; Figure S6: The docking complex and interactions of best docked compounds with Heat Shock Protein 90 (BxHSP90) from B. xylophilus; Figure S7: The docking complex and interactions of best docked compounds with Venom allergen Protein-3 (BxVAP-3) from B. xylophilus; Figure S8: The docking complex and interactions of best docked compounds with $\beta$-Tubulin (BxTUB) from B. xylophilus; Table S1: The measured quality factor values along with ramachandrn plot residue distributions for the modelled proteins; Table S2: The predicted molecular properties confined to the druglike properties (based on Lipinski's rule of five) and biological activity prediction (antihelmentics); Table S3: The 15 compounds with nematicidal activity considered in this study for docking against five targets from B. xylophilus; Table S4: Docking interactions of the binding site residues with all the 15 compounds against Cathepsin L-Like cysteine proteinase (BxCLCP) from B. xylophilus; Table S5: Docking interactions of the binding site residues with all the 15 compounds against 2-cysteine peroxiredoxin (BxPRX) from B. xylophilus; Table S6: Docking interactions of the binding site residues with all the 15 compounds against Heat Shock Protein 90 (BxHSP90) from B. xylophilus; Table S7: Docking interactions of the binding site residues with all the 15 compounds against Venom allergen Protein-3 (BxVAP-3) from B. xylophilus; Table S8: Docking interactions of the binding site residues with all the 15 compounds against $\beta$-Tubulin (BxTUB) from B.xylophilus; Table S9: DFT calculations pertaining to the molecular chemical reactivity for Amocarzine, flubendazole and Mebendazole.

Author Contributions: Conceptualization, G.S., S.K.L. and J.J.; Data curation, G.S.; Methodology, G.S.; Supervision, J.J.; Writing—original draft, G.S.; Writing—review \& editing, S.K.L. and J.J. 
Funding: This work was supported by a grant from the National Institute of Forest Science (Project No. FE0702-2016-02-2016).

Acknowledgments: We thank the Department of Biotechnology, Mahendra Arts and Science College, Tamilnadu, India for software support (molecular docking). This work was supported by a grant from the National Institute of Forest Science (Project No. FE0702-2016-02-2016).

Conflicts of Interest: The authors declare no conflicts of interest.

\section{References}

1. Cheng, X.; Cheng, F.; Xu, R.; Xie, B. Genetic variation in the invasive process of Bursaphelenchus xylophilus (Aphelenchida: Aphelenchoididae) and its possible spread routes in China. Heredity 2008, 100, 356-365. [CrossRef] [PubMed]

2. Rutherford, T.A.; Webster, J.M. Distribution of pine wilt disease with respect to temperature in North America, Japan, and Europe. Can. J. For. Res. 1987, 17, 1050-1059. [CrossRef]

3. Mamiya, Y. The life history of the pine wood nematode, Bursaphelenchus lignicolus. Jpn. J. Nematol. 1975, 5, $16-25$.

4. Leal, I.; Green, M.; Allen, E.; Humble, L.; Rott, M. Application of a real-time PCR method for the detection of pine wood nematode, Bursaphelenchus xylophilus, in wood samples from lodgepole pine. Nematology 1988, 9, 351-362. [CrossRef]

5. Inácio, M.L.; Nobrega, F.; Vieira, P.; Bonifacio, L.; Naves, P.; Sousa, E.; Mota, M. First detection of Bursaphelenchus xylophilus associated with Pinus nigra in Portugal and in Europe. For. Pathol. 2015, 45, 235-238. [CrossRef]

6. Akbulut, S.; Stamps, W.T. Insect vectors of the pinewood nematode: A review of the biology and ecology of Monochamus species. For. Pathol. 2012, 42, 89-99. [CrossRef]

7. Futai, K. Pine wood nematode, Bursaphelenchus xylophilus. Annu. Rev. Phytopathol. 2013, 51, 61-83. [CrossRef] [PubMed]

8. Jones, J.T.; Moens, M.; Mota, M.; Li, H.; Kikuchi, T. Bursaphelenchus xylophilus: Opportunities in comparative genomics and molecular host-parasite interactions. Mol. Plant Pathol. 2008, 9, 357-368. [CrossRef] [PubMed]

9. Mamiya, Y.; Enda, N. Transmission of Bursaphelenchus lignicolus (Nematoda: Aphelenchoididae) by Monochamus alternatus (Coleoptera: Cerambycidae). Nematologica 1972, 18, 159-162. [CrossRef]

10. James, R.; Tisserat, N.; Todd, T. Prevention of pine wilt of Scots pine (Pinus sylvestris) with systemic abamectin injections. Arboric. Urban For. 2006, 32, 195-201.

11. Gopal, R.M.; Pomroy, W.E.; West, D.M. Resistance of field isolates of Trichostrongylus colubriformis and Ostertagia circumcincta to ivermectin. Int. J. Parasitol. 1999, 29, 781-786. [CrossRef]

12. Kim, J.; Lee, S.-M.; Park, C.G. Bursaphelenchus xylophilus is killed by homologues of 2-(1-undecyloxy)-1-ethanol. Sci. Rep. 2016, 6, 29300. [CrossRef] [PubMed]

13. Scott, J.G.; Roush, R.T.; Liu, N. Selection of high-level abamectin resistance from field-collected house flies. Musca domestica. Experientia 1991, 47, 282-291.

14. Argentine, J.A.; Clark, J.M. Selection for abamectin resistance in Colorado potato beetle (Coleoptera: Chrysomelidae). Pestic. Sci. 1990, 28, 17-24. [CrossRef]

15. Lasota, J.A.; Dybas, R.A. Avermectins, a novel class of compounds: Implications for use in arthropod pest control. Annu. Rev. Entomol. 1991, 36, 91-117. [CrossRef] [PubMed]

16. Kikuchi, T.; Cotton, J.A.; Dalzell, J.J.; Hasegawa, K.; Kanzaki, N.; McVeigh, P.; Takanashi, T.; Tsai, I.J.; Assefa, S.A.; Cock, P.J.; et al. Genomic Insights into the Origin of parasitism in the emerging Plant pathogen Bursaphelenchus xylophilus. PLoS Pathog. 2011, 7, e1002219. [CrossRef] [PubMed]

17. Khanna, V.; Ranganathan, S. In silico approach to screen compounds active against parasitic nematodes of major socioeconomic importance. BMC Bioinform. 2011, 12, S25. [CrossRef] [PubMed]

18. Guiliano, D.B.; Hong, X.; McKerrow, J.H.; Blaxter, M.L.; Oksov, Y.; Liu, J.; Ghedin, E.; Lustigman, S. A gene family of cathepsin L-like proteases of filarial nematodes are associated with larval molting and cuticle and eggshell remodeling. Mol. Biochem. Parasitol. 2004, 136, 227-242. [CrossRef] [PubMed]

19. Fu, H.; Ren, J.; Huang, L.; Li, H.; Ye, J. Screening and functional analysis of the peroxiredoxin specifically expressed in Bursaphelenchus xylophilus-The causative agent of pine wilt disease. Int. J. Mol. Sci. 2014, 15, 10215-10232. [CrossRef] [PubMed] 
20. Wang, F.; Wang, Z.; Li, D.; Chen, Q. Identification and characterization of a Bursaphelenchus xylophilus (Aphelenchida: Aphelenchoididae) thermotolerance-related gene: Bx-hsp90. Int. J. Mol. Sci. 2012, 16, 8819-8833. [CrossRef] [PubMed]

21. Kang, J.S.; Koh, Y.H.; Moon, Y.S.; Lee, S.H. Molecular properties of a venom allergen-like protein suggest a parasitic function in the pinewood nematode Bursaphelenchus xylophilus. Int. J. Parasitol. 2012, 42, 63-70. [CrossRef] [PubMed]

22. Taylor, C.M.; Wang, Q.; Rosa, B.A.; Huang, S.C.C.; Powell, K.; Schedl, T.; Pearce, E.J.; Abubucker, S.; Mitreva, M. Discovery of Anthelmintic Drug Targets and Drugs Using Chokepoints in Nematode Metabolic Pathways. PLoS Pathog. 2013, 9, e1003505. [CrossRef] [PubMed]

23. Lacey, E. Mode of action of benzimidazoles. Parasitol. Today 1990, 6, 112-115. [CrossRef]

24. Taylor, D. The Pharmaceutical industry and the future of drug development. In Pharmaceuticals in the Environment; Hester, R.E., Harrison, R.M., Eds.; The Royal Society of Chemistry: London, UK, 2015; pp. 1-33.

25. Xue, Y.; Shui, G.; Wenk, M.R. TPS1 drug design for rice blast disease in Magnaporthe oryzae. SpringerPlus 2014, 3, 18. [CrossRef] [PubMed]

26. Babu, R.O.; Krishna, P.B.; Eapen, S.J. Virtual screening and in vitro assay to explore novel inhibitors from black pepper against potential targets of Radopholus similis. Int. J. Comput. Appl. 2014, 86, 35-43.

27. Altschul, S.F.; Gish, W.; Miller, W.; Myers, E.W.; Lipman, D.J. Basic local alignment search tool. J. Mol. Biol. 1990, 215, 403-410. [CrossRef]

28. Berman, H.M.; Battistuz, T.; Bhat, T.N.; Bluhm, W.F.; Bourne, P.E.; Burkhardt, K.; Feng, Z.; Gilliland, G.L.; Iype, L.; Jain, S.; et al. The protein data bank. Acta Crystallogr. D Biol. Crystallogr. 2002, 58, 899-907. [CrossRef] [PubMed]

29. Yang, A.S.; Honig, B. An integrated approach to the analysis and modeling of protein sequences and structures. III. A comparative study of sequence conservation in protein structural families using multiple structural alignments. J. Mol. Biol. 2000, 301, 691-711. [CrossRef] [PubMed]

30. Rost, B. Twilight zone of protein sequence alignments. Protein Eng. 1999, 12, 85-94. [CrossRef] [PubMed]

31. Sali, A.; Blundell, T.L. Comparative protein modelling by satisfaction of spatial restraints. J. Mol. Biol. 1993, 234, 779-815. [CrossRef] [PubMed]

32. Fiser, A.; Sali, A. Modeller: Generation and refinement of homology-based protein structure models. Methods Enzymol. 2003, 374, 461-491. [PubMed]

33. SAVES Server. Available online: http://services.mbi.ucla.edu/SAVES/ (accessed on 28 November 2017).

34. Laskowski, R.A.; MacArthur, M.W.; Moss, D.S.; Thornton, J.M. PROCHECK a program to check the stereo chemical quality of protein structure, J. Appl. Cryst. 1993, 26, 283-291. [CrossRef]

35. Eisenberg, D.; Lüthy, R.; Bowie, J.U. VERIFY3D: Assessment of protein models with three-dimensional profiles. Methods Enzymol. 1997, 277, 396-404. [PubMed]

36. Colovos, C.; Yeates, T.O. ERRAT: An empirical atom-based method for validating protein structures. Protein Sci. 1993, 2, 1511-1519. [CrossRef] [PubMed]

37. Binkowski, T.A.; Naghibzadeh, S.; Liang, J. CASTp: Computed atlas of surface topography of proteins. Nucleic Acids Res. 2003, 31, 3352-3355. [CrossRef] [PubMed]

38. Filimonov, D.A.; Poroikov, V.V. PASS: Computerized prediction of biological activity spectra for chemical substances. In Bioactive Compound Design: Possibilities for Industrial Use; BIOS Scientific: Oxford, UK, 1996; pp. 47-56.

39. Leelananda, S.P.; Lindert, S. Computational methods in drug discovery. Beilstein J. Org. Chem. 2016, 12, 2694-2718. [CrossRef] [PubMed]

40. Lipinski, C.A. Lead-and drug-like compounds: The rule-of-five revolution. Drug Discov. Today Technol. 2004, 1,337-341. [CrossRef] [PubMed]

41. Sharma, O.P.; Pan, A.; Hoti, S.L.; Jadhav, A.; Kannan, M.; Mathur, P.P. Modeling, docking, simulation, and inhibitory activity of the benzimidazole analogue against $\beta$-tubulin protein from Brugia malayi for treating lymphatic filariasis. Med. Chem. Res. 2012, 21, 2415-2427. [CrossRef]

42. Sen, K.D.; Mingos, D.M.P. Chemical Hardness: Structure and Bonding; Springer: Berlin, Germany, 1993.

43. The UniProt Consortium. UniProt: The universal protein knowledgebase. Nucleic Acids Res. 2017, 45, D158-D169. 
44. Thompson, J.D.; Higgins, D.G.; Gibson, T.J. Clustal W: Improving the sensitivity of progressive multiple sequence alignment through sequence weighting position-specific gap penalties and weight matrix choice. Nucleic Acids Res. 1994, 22, 4673-4680. [CrossRef] [PubMed]

45. Scott, W.R.; Hünenberger, P.H.; Tironi, I.G.; Mark, A.E.; Billeter, S.R.; Fennen, J.; Torda, A.E.; Huber, T.; Krüger, P.; van Gunsteren, W.F. The GROMOS biomolecular simulation program package. J. Phys. Chem. A 1999, 103, 3596-3607. [CrossRef]

46. Kaplan, W.; Littlejohn, T.G. Swiss-PDB viewer (deep view). Brief. Bioinform. 2001, 2, 195-197. [CrossRef] [PubMed]

47. Irwin, J.J.; Shoichet, B.K. ZINC-A Free Database of Commercially Available Compounds for Virtual Screening. J. Chem. Inf. Model. 2005, 45, 177-182. [CrossRef] [PubMed]

48. Schellhammer, I.; Rarey, M. FlexX-Scan: Fast, structure-based virtual screening. Proteins Struct. Funct. Bioinform. 2004, 57, 504-517. [CrossRef] [PubMed]

49. Stierand, K.; Rarey, M. PoseView-Molecular interaction patterns at a glance. J. Cheminform. 2010, 2 (Suppl. 1), P50. [CrossRef]

50. Frisch, M.J.; Trucks, G.W.; Schlegel, H.B.; Scuseria, G.E.; Robb, M.A.; Cheeseman, J.R.; Scalmani, G.; Barone, V.; Mennucci, B.; Petersson, G.A.; et al. Gaussian 09, Revision A.01; Gaussian, Inc.: Wallingford, CT, USA, 2009.

51. Foresman, J.B.; Frisch, A. Exploring Chemistry with Electronic Structure Methods; Gaussian: Pittsburgh, PA, USA, 1995.

52. Pauling, L. The Nature of the Chemical Bond; Cornell University Press: Ithaca, NY, USA, 1960.

53. Senet, P. Chemical hardnesses of atoms and molecules from frontier orbitals. Chem. Phys. Lett. 1997, 275, 527-532. [CrossRef]

54. Parr, R.G.; Pearson, R.G. Absolute hardness: Companion parameter to absolute electronegativity. J. Am. Chem. Soc. 1983, 105, 7512-7516. [CrossRef]

Sample Availability: All the compounds are available from Pubchem and ZINC database.

(C) 2018 by the authors. Licensee MDPI, Basel, Switzerland. This article is an open access article distributed under the terms and conditions of the Creative Commons Attribution (CC BY) license (http://creativecommons.org/licenses/by/4.0/). 